\title{
Endogenous Surfactant Metabolism in Newborn Infants with and without Respiratory Failure
}

\author{
KAJSA BOHLIN, ASSAAD MERCHAK, KIMBERLY SPENCE, BRUCE W. PATTERSON, AND \\ AARON HAMVAS \\ Division of Newborn Medicine, the Edward Mallinckrodt Department of Pediatrics, Washington University \\ School of Medicine, and St. Louis Children's Hospital, St. Louis, Missouri 63110, U.S.A. [K.B., A.M., K.S., \\ A.H.]; Department of Pediatrics, Huddinge University Hospital, Karolinska Institute, Stockholm, Sweden \\ [K.B.]; and Center for Human Nutrition, Division of Geriatrics and Nutritional Science, Department of Internal \\ Medicine, Washington University School of Medicine, St. Louis, Missouri 63110, U.S.A. [B.W.P.]
}

\begin{abstract}
Studies using stable isotopically labeled glucose and palmitate as precursors of pulmonary surfactant synthesis have demonstrated slow surfactant turnover in premature infants with respiratory distress syndrome (RDS). However, only limited data about surfactant turnover are available for term infants. Because acetate is a direct precursor of de novo synthesized surfactant fatty acid, we measured $\left[1-{ }^{13} \mathrm{C}_{1}\right]$ acetate incorporation into surfactant of term infants without respiratory dysfunction (control group), preterm infants with RDS, and term infants with primary respiratory failure to determine whether stable isotopically labeled acetate would yield similar results to previous studies of preterm infants with RDS and, furthermore, would distinguish normal from abnormal surfactant turnover. Despite similar amounts of phospholipids and acetate precursor enrichment, the control group had higher fractional synthetic rate and shorter half-life of clearance than preterm infants with RDS, (fractional synthetic rate, $15.4 \pm 2.4$ versus $2.2 \pm 0.4 \% / \mathrm{d}, p<0.001$; half-life of clearance, $27 \pm 3$ versus $105 \pm 11 \mathrm{~h}, p<0.001$ ). Term infants with severe respiratory failure had a lower fractional synthetic rate than those with mild disease $(2.9 \pm 0.6$ versus $13.8 \pm 3.5 \% / \mathrm{d}, p=0.014)$ and a reduced amount of phospholipids recovered from tracheal aspirates $(54 \pm 17$ versus $300 \pm 28 \mathrm{nmol}$, severe versus mild disease, respectively, $p<$
\end{abstract}

0.001). The amount of phospholipids in tracheal aspirates correlated inversely with disease severity, $(r=-0.75, p=0.01)$. We conclude that normal surfactant turnover in term infants is faster than in preterm infants with RDS. Surfactant turnover in term infants with severe respiratory failure is similar to that of preterm infants with RDS, suggesting either delayed maturity of the surfactant system or disruption from the underlying disease process. (Pediatr Res 54: 185-191, 2003)

$\quad$ Abbreviations
DPPC, dipalmitoylphosphatidylcholine
$\mathbf{E}_{\mathbf{m a x}}$, maximum enrichment
FSR, fractional synthetic rate
Fio $_{\mathbf{2}}$, fraction of inspired oxygen
$\mathbf{G C}_{\mathbf{M} S, \text { gas chromatography/mass spectrometry }}$
MIDA, mass isotopomer distribution analysis
RDS, respiratory distress syndrome
T1/2, half-life of clearance
TA, tracheal aspirate
$\mathbf{T}_{\text {app }}$, time of appearance
$\mathbf{T}_{\mathbf{m a x}}$, time of maximum enrichment
TTR, tracer to tracee ratio

RDS in premature infants is caused by a quantitative deficiency of pulmonary surfactant, but understanding of surfactant metabolism in the neonatal period is limited (1). Surfactant

Received November 12, 2002; accepted March 19, 2003

Correspondence: Aaron Hamvas, M.D., Division of Newborn Medicine, St. Louis Children's Hospital, 1 Children's Place, St. Louis, MO 63110, U.S.A.; e-mail: hamvas@kids.wustl.edu

Supported by grants from European Society for Pediatric Research (K.B.), Majblommans Riksförbund (K.B.), Southern Medical Association (A.M.), NIH P30 DK56341 (Clinical Nutrition Research Unit, B.W.P.), and NIH R01 HL 65385 (A.H.).

Presented in abstract form at the Society for Pediatric Research, May 2001, Baltimore, MD, U.S.A., and the European Society for Pediatric Research, September 2002, Utrecht, The Netherlands.

DOI: 10.1203/01.PDR.0000075084.56255.E0 is synthesized, assembled, secreted, degraded, and recycled in a complex metabolic cycle (2). The principal surface-active material in surfactant is DPPC. Fatty acids for DPPC synthesis in the pulmonary type II cell can be derived from catabolism of triacylglycerols and recycled phospholipids, from preformed plasma fatty acids (i.e. palmitate), or from de novo synthesis from precursors such as glucose, lactate, or acetate (3).

Animal studies using radioactively labeled palmitate, acetate, and choline as precursors of surfactant synthesis have demonstrated that surfactant turnover (the end result of synthesis, secretion, recycling, and clearance) is slower in newborns than in adult animals (4-8). For example, the T1/2 of labeled endogenous surfactant was more than $150 \mathrm{~h}$ in prema- 
ture rabbits, $50 \mathrm{~h}$ in 3-d-old newborn rabbits, and only $20 \mathrm{~h}$ in adult rabbits (5-7). In term and preterm lambs, the rate of incorporation of radiolabeled palmitate into newly synthesized surfactant was similar, although without measurements of the enrichment of the precursor pool, the net surfactant synthesis rate could not be calculated from the rate of incorporation (8). In vitro studies in fetal and neonatal lung slices from different species have shown increasing fatty acid synthesis toward the end of gestation $(9,10)$.

The availability of stable isotopically labeled precursors of pulmonary surfactant has enabled human studies of surfactant production and clearance (11-16). Studies in premature baboons and adult pigs using stable isotopically labeled glucose, acetate, and palmitate have yielded results that are consistent with animal studies using radiolabeled precursors and provide evidence of the validity of the technique $(17,18)$. Human studies using stable isotopically labeled glucose, palmitate, and linoleate in preterm infants with RDS and older infants with respiratory failure have also demonstrated slow surfactant turnover, which is also consistent with the aforementioned animal studies $(11,12,15,16)$. Cogo et al. (19), using stable isotopically labeled palmitate as a measure of surfactant metabolism from preformed plasma fatty acids, have performed the only study in infants without lung disease. They found no differences in the stable isotope-derived indices of metabolism between the normal infants and those with congenital diaphragmatic hernia. However, the surfactant turnover was faster in these normal infants than in preterm infants with RDS in another study from the same group (15).

Stable isotopically labeled acetate offers several potential advantages over the other tracers as a marker of surfactant metabolism in humans: 1) it is the direct precursor for de novo synthesis of surfactant fatty acid; 2) it may be preferred to glucose in the neonatal lung and is exclusively incorporated into fatty acids in vitro whereas 20 to $40 \%$ of glucose is used for glyceride-glycerol (20-22); 3) a higher enrichment in the acetate precursor pool can be achieved for more reliable measurements at a lower cost than either glucose or palmitate and its preparation for infusion is less complex than that of palmitate; and 4) MIDA can be used to measure the direct intracellular precursor pool (23-25). The enrichment of the precursor pool reflects the availability of tracer for surfactant synthesis and further permits distinguishing tracer metabolism from surfactant metabolism.

Therefore, to determine whether stable isotopically labeled acetate would 1 ) detect the slow surfactant turnover seen in previous studies of preterm infants with RDS using labeled glucose, and 2) distinguish normal from abnormal surfactant turnover, we used $\left[1-{ }^{13} \mathrm{C}_{1}\right]$ acetate to evaluate endogenous surfactant production and clearance in preterm newborns with RDS and term newborns with and without respiratory failure.

\section{METHODS}

Study design. Infants admitted to the Neonatal or Pediatric Intensive Care Units at St. Louis Children's Hospital were eligible if they had airway access and met the following criteria:
1. Control infants $(n=7)$ : gestational age $\geq 37 \mathrm{wk}$ and less than 6 mo of age with clear lung parenchyma on chest radiograph and requiring less than $0.3 \mathrm{FiO}_{2}$.

2. Preterm infants with $\operatorname{RDS}(n=12)$ : gestational age $<28$ wk and $24 \mathrm{~h}$ of age with diffuse reticulogranular infiltrates and air-bronchograms on chest radiograph.

3 . Term infants with respiratory failure $(n=10)$ : gestational age $\geq 37 \mathrm{wk}$ and less than 6 mo of age, with onset of respiratory failure at birth.

Infants with chromosomal anomalies and imminent death were excluded.

All infants received $2.9 \mathrm{mmol} / \mathrm{kg}$ of $\left[1-{ }^{13} \mathrm{C}_{1}\right]$ acetate (Cambridge Isotope Laboratories, Inc., Andover, MA, U.S.A.) administered as the sodium salt, dissolved in 5 or $10 \%$ dextrose, and given as a continuous i.v. infusion during $24 \mathrm{~h}$. For the infusion period, fluid and sodium intake were adjusted to maintain preinfusion rates. TAs were collected in a standardized fashion at the start of the tracer infusion (time 0 ) and every $6-12 \mathrm{~h}$ for $14 \mathrm{~d}$ or until extubation and stored at $-70^{\circ} \mathrm{C}$ until processed (11). The infant's medical team determined medical care, including ventilatory management.

Written parental informed consent was obtained. The Washington University Human Studies Committee approved the study.

Analytical procedures. TA samples were processed to yield disaturated phospholipids by a modification (25) of the method of Mason et al. (26). Briefly, after thawing, TA samples were centrifuged, and the supernatant was dried. For quantification, 101 nmol of internal standard (diheptadecanoylphosphatidylcholine, C17:0-PC; Sigma Chemical Co., Inc., St. Louis, MO, U.S.A.) was added. After chloroform-methanol extraction, osmium tetroxide was added to each specimen, and the samples were eluted over neutral alumina columns with chloroformmethanol-ammonium hydroxide. Methyl esters of the fatty acids in the eluates were prepared by adding acetyl chloride in methanol and incubating at $70^{\circ} \mathrm{C}$ for $30 \mathrm{~min}$. The fatty acid species in each TA sample were quantified with gas chromatography using a Hewlett-Packard model 5890 (Palo Alto, CA, U.S.A.) system equipped with a flame ionization detector. We have previously shown that phospholipids are recovered by this procedure, and the fatty acid composition is $>95 \%$ saturated fatty acids, of which $>98 \%$ is palmitic acid (25). By comparison to the internal standard, the mean amount of recovered disaturated phospholipids (in nanomoles) in all TAs from each patient was calculated on the basis of the measured percent composition of palmitate.

The isotopic enrichment of ${ }^{13} \mathrm{C}$ in palmitate was measured by GC/MS (model 5973; Hewlett-Packard). Enrichment is expressed as TTR, representing the molar ratio of labeled to unlabeled palmitate in the sample.

Indices of surfactant metabolism were determined from each individual curve of isotopic enrichment over time, as described previously (11-16). The $\mathrm{T}_{\text {app }}$ of tracer in the surfactant palmitate (hours), the $\mathrm{E}_{\max }$ (TTR, percent), and $\mathrm{T}_{\max }$ (hours) were calculated from the linear upslope of the enrichment versus time curve, whereas the T1/2 (hours) was calculated from monoexponential fitting of the downslope of the enrichment versus time curve. 
In contrast to previous studies of surfactant metabolism using glucose or palmitate in which precursor enrichment was measured in the plasma, using GC/MS we measured the relative proportions of surfactant palmitate with one and two $\left[1-{ }^{13} \mathrm{C}_{1}\right]$ acetate subunits incorporated and used MIDA to determine isotopic enrichment of the direct precursor pool (intracellular acetate) (23-25). Briefly, the acetate precursor enrichment $(p)$ for palmitate synthesis was determined from the ratio $(R)$ of palmitate molecules with two and one labeled acetate units incorporated using the equation:

$$
p=2 R /[(n-1)+2 R]
$$

where $n=8$ acetate precursor subunits for palmitate synthesis. From this acetate precursor enrichment, the theoretical enrichment $\left(E_{p}\right)$ that will be achieved in singly labeled palmitate if all of the surfactant palmitate arose by de novo synthesis is determined using the following binomial equation:

$$
E_{p}=n p(1-p)^{n-1}
$$

where $n=8$ acetate units. The FSR, the fraction of the surfactant pool that is actually formed by de novo synthesis per day (percent per day) was calculated by dividing the slope of the increase in the singly labeled palmitate enrichment-time curve by the palmitate precursor enrichment:

$$
\mathrm{FSR}=(\triangle E / \triangle t) \cdot 1 / E_{p}
$$

In contrast to previous animal studies using radioactive tracers to pulse-label surfactant, the MIDA approach requires a constant enrichment in the acetate pool, which can only be achieved with a longer infusion.

Severity of lung disease was assessed by a score derived from the integrated area under the curve for average daily $\mathrm{Fio}_{2}$ $\times$ mean airway pressure over time, divided by number of days studied (27).

Two-tailed $t$ tests were used for normally distributed data, Kruskal-Wallis tests for nonnormally distributed data, Fisher's exact test for categorical data, and Pearson coefficients for correlation analysis (28). Statistical analyses were performed using Statistical Analysis System (SAS, version 8.1; SAS Institute, Cary, NC, U.S.A.).

\section{RESULTS}

Control infants and preterm infants with RDS. To determine normal values for stable isotopically derived indices of surfactant metabolism, control infants without clinically evident respiratory dysfunction were compared with preterm infants with RDS, an extensively studied population known to have decreased surfactant turnover. Patient characteristics are shown in Table 1. The underlying diagnoses for the control infants were hypoxic ischemic encephalopathy, micrognathia, congenital hypotonia, subdural hematoma, central hypoventilation syndrome, choanal atresia, and severe tracheomalacia. All preterm infants with RDS received one to three doses of exogenous surfactant $12-24 \mathrm{~h}$ before the start of the study. No additional doses of exogenous surfactant were given after
Table 1. Characteristics of control infants and preterm infants with RDS

\begin{tabular}{lcc}
\hline & $\begin{array}{c}\text { Controls } \\
(n=7)\end{array}$ & $\begin{array}{c}\text { Preterm RDS } \\
(n=12)\end{array}$ \\
\hline Weight at study start $(\mathrm{kg})$ & $3.7 \pm 0.4$ & $0.72 \pm 0.03$ \\
Gestational age (wk) & $38.5 \pm 0.7$ & $25.5 \pm 0.3$ \\
Age at study start (median, range) & $24(8-180) \mathrm{d}$ & $25(23-43) \mathrm{h}$ \\
Sex (male:female) & $5: 2$ & $5: 7$ \\
Race (white:black:Hispanic) & $5: 1: 1$ & $1: 11: 0$ \\
Exogenous surfactant, $n(\%)$ & $0(0)$ & $12(100)$ \\
Prenatal steroids, $n(\%)$ & $0(0)$ & $8(67)$ \\
Ventilation mode (CV:HFOV) & $6: 0^{*}$ & $8: 4$ \\
Disease severity score $\dagger$ & $1.6 \pm 0.3$ & $3.7 \pm 0.4$ \\
Survival at discharge, $n(\%)$ & $6(86)$ & $9(75)$
\end{tabular}

Data are group mean \pm SEM.

* One infant breathing spontaneously through tracheostomy.

$\dagger$ Integrated area under the curve of average daily $\mathrm{FiO}_{2} \times$ mean airway pressure over time, divided by number of days studied.

Abbreviations: CV, conventional ventilation; HFOV, high-frequency oscillatory ventilation.

initiation of the tracer infusion; no infants received corticosteroids during the study period.

The ${ }^{13} \mathrm{C}$-enrichments of palmitate from TA-derived saturated phospholipids with time are shown in Figure 1. The indices of surfactant metabolism, calculated from the individual isotopic enrichment curves, are displayed in Table 2. In contrast to preterm infants, FSR was significantly higher and T1/2 significantly shorter in the control infants, indicating more rapid turnover in these term infants. Preterm infants with RDS treated with conventional ventilation or high-frequency oscillatory ventilation had similar FSR and T1/2 (data not shown). There was no difference in the availability of tracer for surfactant synthesis as shown by the similar enrichment of the acetate precursor pool. The mean absolute amounts of surfactant phospholipids in TAs were similar between the two groups. When normalized for body weight at the time of the study, the preterm infants with RDS had a significantly higher value (Table 2).

One control infant underwent two studies 3 wk apart (at age 24 and $45 \mathrm{~d}$ ). The enrichment curves and metabolic indices were nearly identical to one another with FSR of 25.4 and

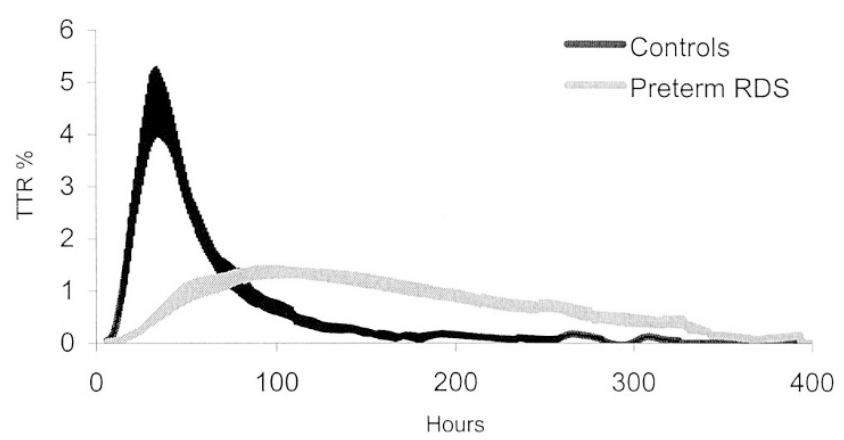

Figure 1. Enrichment of singly labeled palmitate (palmitate that has incorporated one ${ }^{13} \mathrm{C}$-acetate unit) in serial TAs from control infants and preterm infants with RDS after i.v. infusion of $\left[1-{ }^{13} \mathrm{C}_{1}\right]$ acetate. The curves were obtained by linear interpolation at hourly intervals for each individual subject, then obtaining the mean \pm SEM for each group. Tracer incorporation into surfactant and clearance from the airways is significantly faster in the control infants. 
Table 2. Indices of surfactant metabolism in control infants and preterm infants with $R D S$

\begin{tabular}{lccr}
\hline & $\begin{array}{c}\text { Controls } \\
(n=7)\end{array}$ & $\begin{array}{c}\text { Preterm RDS } \\
(n=12)\end{array}$ & \multicolumn{1}{c}{$p$} \\
\hline $\mathrm{T}_{\text {app }}(\mathrm{h})$ & $7 \pm 0.9$ & $13 \pm 1.6$ & 0.005 \\
$\mathrm{FSR}(\% / \mathrm{d})$ & $15.2(6.9-25.4)$ & $1.7(0.9-5.1)$ & $<0.001$ \\
$\mathrm{~T}_{\max }(\mathrm{h})$ & $35(32-43)$ & $82(48-147)$ & $<0.001$ \\
$\mathrm{E}_{\max }(\mathrm{TTR} \%)$ & $4.4(2.2-7.9)$ & $1.6(0.9-2.7)$ & $<0.001$ \\
$\mathrm{~T}_{1 / 2}(\mathrm{~h})$ & $28 \pm 3.2$ & $106 \pm 11.6$ & $<0.001$ \\
$\quad \begin{array}{l}\text { Surfactant phospholipid } \\
\quad \text { in TA (nmol) }\end{array}$ & $235 \pm 35$ & $206 \pm 27$ & 0.51 \\
$\quad \begin{array}{l}\text { Surfactant phospholipid } \\
\quad \text { in TA (nmol/kg) }\end{array}$ & $72(35-94)$ & $337(148-520)$ & 0.002 \\
$\quad \begin{array}{l}\text { Acetate precursor } \\
\quad \text { enrichment }(\%)\end{array}$ & $8.2 \pm 0.6$ & $7.1 \pm 0.6$ & 0.21 \\
\hline
\end{tabular}

Data are group mean \pm SEM for normally distributed data and median (range) for nonnormally distributed data.

$25.2 \% / \mathrm{d}$ and $\mathrm{T} 1 / 2,25.0$ and $25.4 \mathrm{~h}$, respectively, suggesting that the measurements using this technique are reproducible (Fig. 2).

Term infants with respiratory failure. We next studied 10 term infants who exhibited respiratory failure at birth but were studied between birth and 5 mo of age. The dichotomous distribution of the disease severity score permitted stratifying the infants into two groups: those with mild disease (respiratory severity score $<5, n=6$ ) and those with severe disease (respiratory severity score $>8, n=4$ ). Patient characteristics and outcome data are shown in Table 3. Five infants (four with mild disease and one with severe disease) presented at birth with respiratory distress requiring mechanical ventilation and had bilateral granular infiltrates on chest radiograph; two others had suspected, but not culture proven, pneumonia with pneumothoraces (one with mild and one with severe disease); and three were studied while awaiting lung transplantation [one with alveolar proteinosis of unknown origin (severe), one with respiratory failure of unknown origin (mild), and one with refractory respiratory failure after congenital diaphragmatic hernia repair (severe)]. None of these infants had an inherited disorder of surfactant protein $\mathrm{B}$ or $\mathrm{C}$ metabolism.

The ${ }^{13} \mathrm{C}$-enrichment curves for the infants with mild and severe disease are shown in Figure 3 and the indices of

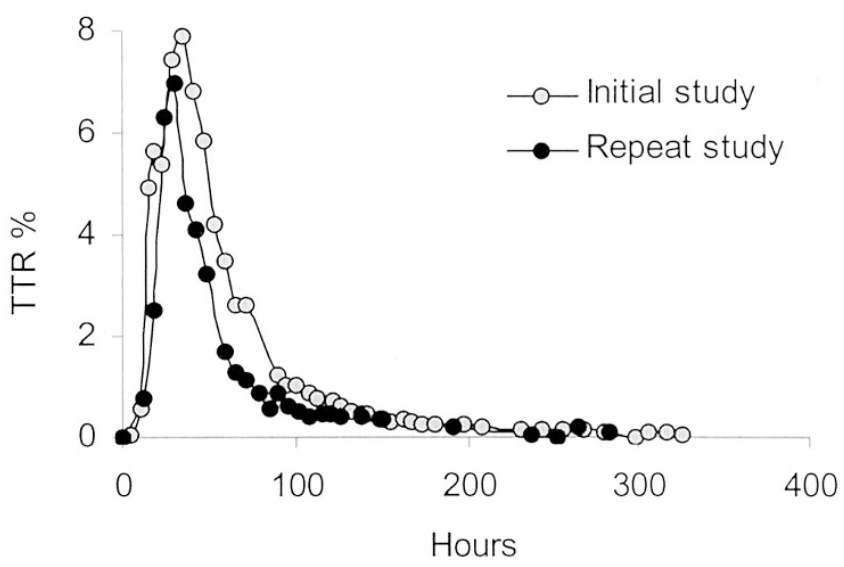

Figure 2. ${ }^{13} \mathrm{C}$-enrichment in palmitate in serial TAs from one control infant after two infusions of $\left[1-{ }^{13} \mathrm{C}_{1}\right]$ acetate separated by $3 \mathrm{wk}$. The enrichment curves and indices of surfactant metabolism are nearly identical in the two studies.
Table 3. Characteristics of term infants with respiratory failure

\begin{tabular}{lccl}
\hline & $\begin{array}{c}\text { Mild* } \\
(n=6)\end{array}$ & $\begin{array}{c}\text { Severe* } \\
(n=4)\end{array}$ & $p$ \\
\hline Weight at study start $(\mathrm{kg})$ & $3.7 \pm 0.4$ & $3.6 \pm 0.2$ & 0.66 \\
Gestational age (wk) & $38.0 \pm 0.5$ & $37.5 \pm 0.5$ & 0.36 \\
Age at study start (median, range) & $4(1-162) \mathrm{d}$ & $35(4-124) \mathrm{d}$ & 0.19 \\
Sex (male:female) & $4: 2$ & $2: 2$ & 1.0 \\
Race (white:black:Hispanic) & $5: 0: 1$ & $4: 0: 0$ & 1.0 \\
Exogenous surfactant, $n(\%) \dagger$ & $1(17)$ & $1(25)$ & 0.87 \\
Steroid treatment, $n(\%) \ddagger$ & $1(17)$ & $0(0)$ & 1.0 \\
Ventilation mode (CV:HFOV) & $6: 0$ & $2: 2$ & 0.13 \\
Disease severity score & $2.7 \pm 0.6$ & $13.6 \pm 2.8$ & 0.014 \\
Duration of study (d)§ & $6 \pm 1.7$ & $12 \pm 1.2$ & 0.036 \\
Survival, $n(\%) \mathbb{I}$ & $6(100)$ & $2(50) \|$ & 0.13
\end{tabular}

Data are group mean \pm SEM.

$*$ Mild, disease severity score $<5$; severe, disease severity score $>8$.

$\dagger$ Within 1 wk before study start.

\$ Within 1 mo before study start.

$\S$ From the start of isotope infusion until extubation, death, or the 14-d study end point.

II At discharge or time of lung transplantation.

\| Of survivors, one to lung transplant, one transferred out on continuous positive-airway pressure.

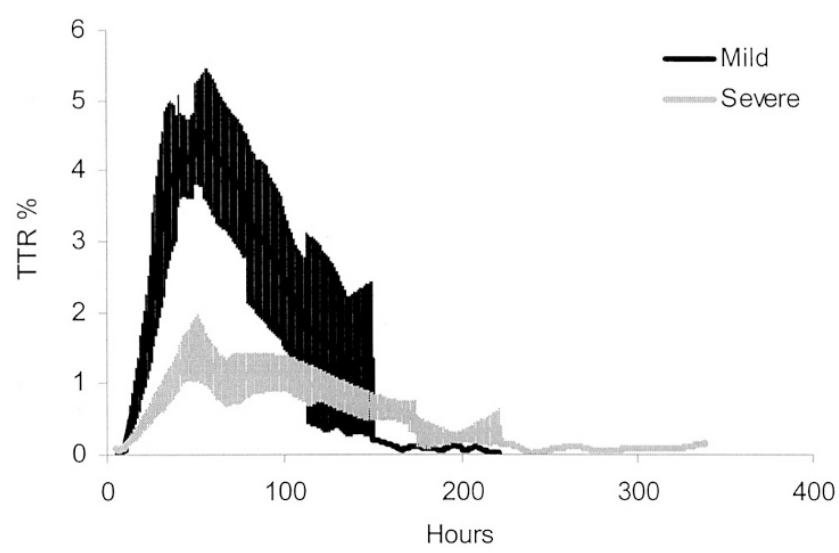

Figure 3. ${ }^{13} \mathrm{C}$-enrichment in palmitate in serial TAs from term infants with mild and severe lung disease after i.v. infusion of $\left[1{ }^{13} \mathrm{C}_{1}\right]$ acetate. The curves were obtained as described in Figure 1. Tracer incorporation into surfactant and clearance from the airways is significantly faster in term infants with mild lung disease.

surfactant metabolism in Table 4. Three infants with mild disease were extubated within the first $72 \mathrm{~h}$ of study, resulting in shorter study duration and preventing calculations of complete sets of indices. The enrichment curves and the indices of surfactant metabolism for infants with mild disease were similar to those of the control infants, whereas the enrichment curves and metabolic indices for infants with severe disease resembled those of preterm infants with RDS. There were no significant differences in FSR or T1/2 between infants with mild disease and control infants or between infants with severe disease and preterm infants with RDS. The acetate precursor enrichment was similar in infants with mild and severe disease (Table 4). One infant each with mild and severe disease received exogenous surfactant treatment approximately $48 \mathrm{~h}$ before the start of the study. The enrichment curves, amounts of phospholipid in the TA, and metabolic indices for these infants were consistent with the other untreated infants with similar disease severity (data not shown). 
Table 4. Indices of surfactant metabolism in term infants with respiratory failure

\begin{tabular}{|c|c|c|c|}
\hline & $\begin{array}{l}\text { Mild } \\
(n=6)\end{array}$ & $\begin{array}{l}\text { Severe } \\
(n=4)\end{array}$ & $p$ \\
\hline $\mathrm{T}_{\text {app }}(\mathrm{h})$ & $9 \pm 1.2$ & $11 \pm 3.7$ & 0.61 \\
\hline FSR $(\% / d)$ & $10.7(7.2-30.2)$ & $2.9(1.6-4.3)$ & 0.01 \\
\hline $\mathrm{T}_{\max }(\mathrm{h})$ & $\begin{array}{r}46 \pm 4.2 \\
(n=5)\end{array}$ & $53 \pm 6.3$ & 0.38 \\
\hline $\mathrm{E}_{\max }(\mathrm{TTR} \%)$ & $5.6 \pm 0.8$ & $1.8 \pm 0.3$ & 0.007 \\
\hline $\mathrm{T}_{1 / 2}(\mathrm{~h})$ & $\begin{array}{c}38 \pm 11.3 \\
(n=3)\end{array}$ & $63 \pm 10.3$ & 0.16 \\
\hline $\begin{array}{l}\text { Surfactant phospholipid in } \\
\text { TA (nmol) }\end{array}$ & $300 \pm 28$ & $54 \pm 17$ & 0.003 \\
\hline $\begin{array}{l}\text { Surfactant phospholipid in } \\
\text { TA }(\mathrm{nmol} / \mathrm{kg})\end{array}$ & $59 \pm 8$ & $16 \pm 6$ & 0.005 \\
\hline Precursor enrichment (\%) & $8.2 \pm 1.2$ & $9.9 \pm 2.6$ & 0.53 \\
\hline
\end{tabular}

Data are group mean \pm SEM for normally distributed data and median (range) for nonnormally distributed data. Labels as in Table 3.

The mean amount of surfactant phospholipid in TAs was significantly lower in the infants with severe disease, both with and without normalization for body weight (Table 4). There was an inverse correlation between the amount of phospholipid (both absolute and normalized) and the disease severity score $(r=-0.7, p=0.01)$.

Finally, to evaluate whether timing of the study contributed to the differences in the indices of surfactant metabolism, we compared the seven infants studied in their first week of life to the three infants studied after 2 mo of age and found no differences in stable isotope indices of surfactant metabolism, acetate precursor enrichment, or amount of phospholipids in TA.

\section{DISCUSSION}

Stable isotope methods have only recently been used to evaluate surfactant metabolism in vivo. It should be noted that these methods yield indices that reflect the net result of surfactant synthesis, secretion, recycling, and clearance via macrophages or the upper airway, and are not direct measures of the absolute rate of surfactant synthesis, secretion, or recycling in the alveolar type II cell. Furthermore, because DPPC is specifically enriched in pulmonary surfactant, we are assuming that the palmitate in our disaturated phospholipid extract represents surfactant-derived palmitate. Studies in adult pigs and premature baboons have suggested that TA-derived surfactant is reflective of that in the alveolar space and that these stable isotope techniques yield data about the kinetics of surfactant metabolism that are consistent with previous animal studies $(17,18,29,30)$. These stable isotope techniques have provided similarly consistent data in infants with lung disease who presumably have abnormal surfactant production or clearance. This study now provides additional data to support the utility of these methods. First, although it is only one subject, the reproducibility of the technique is suggested from identical surfactant metabolic indices in the one control infant who underwent two studies. Second, as anticipated, we found faster turnover (higher FSR and shorter T1/2) in the control infants than preterm infants with RDS. More importantly, we used MIDA to estimate the intracellular acetate pool, which reflects the availability of tracer for surfactant synthesis. Thus, apparent differences in the stable isotopically derived measures owing to differences in tracer metabolism can be distinguished from differences in surfactant metabolism. The similar precursor enrichments between preterm infants with RDS and control infants, and between term infants with mild and severe respiratory disease, indicate that the observed differences in endogenous surfactant turnover were therefore not caused by differences in tracer metabolism or availability, but rather were differences in the synthesis or clearance of surfactant.

Previous studies using labeled glucose as a measure of de novo surfactant fatty acid synthesis in preterm infants with RDS demonstrated a $\mathrm{T}_{\text {app }}$ between 10 and $20 \mathrm{~h}$, an FSR of $2-9 \% / \mathrm{d}, \mathrm{T}_{\max }$ of $59-87 \mathrm{~h}$, and a T1/2 of $60-120 \mathrm{~h}$, values that are similar to those of the preterm infants in our study using labeled acetate $[(11,13,14,16)$; Table 3]. Although previous studies using stable isotopes have provided a context for interpreting surfactant production and clearance in preterm infants, comparable data for term infants with and without lung disease are more limited. In the only other study to determine normal values for surfactant metabolic indices, Cogo et al. (19) demonstrated an FSR of $17 \pm 11 \% / d$ using labeled palmitate, which was higher than that of preterm infants with RDS (12 \pm 8\%/d) measured by Cavicchioli et al. (15) in a separate study. Furthermore, Cogo et al. (12) used labeled palmitate and linoleic acid to study older, critically ill infants with varied mechanisms of respiratory failure and found a wide range of values for FSR $(9.6-81.6 \% / d)$ and T1/2 (17-178 h). The use of palmitate as the tracer in these studies makes it difficult to compare their findings to ours because palmitate tracks the direct incorporation of preformed fatty acids into surfactant phospholipids rather than the de novo synthesis of fatty acids, as with glucose or acetate. However, the clear distinction in the stable isotopically derived indices of surfactant metabolism in our term infants with heterogeneous causes of respiratory dysfunction suggests that the infants with more severe disease were similar to the preterm infants with RDS. Whether this slow surfactant turnover and the resulting decrease in the amount of saturated phospholipid in the TA resulted from a developmental lag in surfactant production or resulted from lung injury and type II cell dysfunction, such as seen in acute respiratory distress syndrome in older patients, cannot be determined from this study (31).

With stable isotopes, apparent differences in surfactant metabolism could result from differences in tracer metabolism, as discussed above, from true differences in surfactant production and clearance, or from differences in the size of the unlabeled surfactant pool. That is, a small, unlabeled pool would result in apparent increases in turnover of labeled surfactant. For example, surfactant pool size decreases with increasing postnatal age in animals $(6,32)$. Although the variation in postnatal age in the term infants in our study could influence the FSR and $\mathrm{T} 1 / 2$, we found no differences in these indices between infants studied before and after 2 mo of age. Further studies are necessary to determine whether surfactant pool sizes and metabolic indices change with advancing postnatal age in humans.

Because the size of this pool cannot be measured in infants, we used the amount of disaturated phospholipids in the TA 
samples as an indirect reflection of pool size. These measurements should be interpreted cautiously as they may be influenced by the tracheal suctioning procedure, the rate at which surfactant ascends the tracheobronchial tree, the mode of ventilation, or administration of exogenous surfactant $(14,15,33)$. Hallman et al. (34) have previously reported values for surfactant-treated preterm infants in the same range as ours and also found a linear correlation between the amount of total phospholipids in TAs and the apparent surfactant pool size determined by Fick principle. To determine whether augmenting the unlabeled pool with exogenous surfactant influenced the stable isotope measures of surfactant turnover, Bunt et al. (14) found decreasing FSR with increasing number of doses of exogenous surfactant, as would be anticipated. However, in that study, the infants who received the most surfactant also had the most severe RDS and did not receive antenatal corticosteroids, either of which could have independently resulted in a lower FSR $(13,18)$. Cavicchioli et al. (15) using labeled palmitate as a tracer of surfactant synthesis in preterm infants with RDS, found that exogenous surfactant treatment resulted in later time of appearance and maximum enrichment of label, but were unable to show any effect on either FSR or T1/2. With these caveats in mind, preterm infants with RDS, all of who received exogenous surfactant, had a greater amount of disaturated phospholipid normalized for body weight, but similar absolute amounts of phospholipid in the TAs as control infants. Although this observation does not preclude apparently slower kinetics as a result of isotopic dilution, the similarity of our results with previous studies suggests that the observed differences in surfactant metabolism between the two groups were true differences in surfactant metabolism, as would be anticipated.

In contrast, the term infants with severe respiratory failure had significantly less phospholipid in TAs than any other group, suggesting a smaller pool size. However, the lower FSR and $E_{\max }$ values in these infants directly contradict what would have been anticipated had isotopic dilution contributed to the differences in metabolic indices. Martini et al. (29), using stable isotopically labeled acetate and palmitate, demonstrated that thermal injury in adult pigs decreased the surfactant phosphatidylcholine pool and further decreased FSR, consistent with our observation in the term infants with severe respiratory dysfunction. In premature lambs, smaller alveolar surfactant pool size also correlated with more impaired lung function (35), which supports our finding that the disease severity correlated inversely with the mean amount of surfactant phospholipids in TAs. Thus, our data are again consistent with these studies, which suggests true differences in surfactant production between those term infants with mild and severe disease. The concomitant use of stable isotopically labeled exogenous surfactant preparations will permit the more reliable estimates of surfactant pool size necessary for fully interpreting the indices of endogenous surfactant metabolism $(36,37)$.

\section{CONCLUSIONS}

In summary, these additional studies provide new data that suggest the internal consistency of stable isotope methods for evaluating surfactant metabolism in vivo: the ability to distinguish differences where they should exist, the suggestion of reproducibility, and now the observation that some term infants with compromised pulmonary function have abnormal surfactant metabolism that is similar to that of preterm infants with RDS. Additional studies using these techniques will permit further insight into mechanisms of lung disease in infants in whom surfactant metabolism or function may be disrupted.

Acknowledgments. The authors thank Virgilio Carnielli, M.D., Ph.D., and Luc Zimmerman, M.D., Ph.D., for a fruitful collaboration, F. Sessions Cole, M.D., and Mats Blennow, M.D., Ph.D., for invaluable scientific advice, Junyoung Kwon for GC/MS analyses, Kristina Kloos, Pharm.D., for tracer preparation, and the Neonatal Intensive Care Unit staff at St. Louis Children's Hospital for support and sample collection.

\section{REFERENCES}

1. Avery ME, Mead J 1959 Surface properties in relation to atelectasis and hyaline membrane disease. Am J Dis Child 97:517-523

2. Creuwels LA, van Golde LM, Haagsman HP 1997 The pulmonary surfactant system: biochemical and clinical aspects. Lung 175:1-39

3. Batenburg JJ 1992 Surfactant phospholipids: synthesis and storage. Am J Physiol 262:L367-L385

4. Ikegami M, Jobe A, Nathanielsz PW 1981 The labeling of pulmonary surfactant phosphatidylcholine in newborn and adult sheep. Exp Lung Res 2:197-206

5. Jobe A, Gluck L 1979 The labeling of lung phosphatidylcholine in premature rabbits. Pediatr Res 13:635-640

6. Jacobs H, Jobe A, Ikegami M, Jones S 1982 Surfactant phosphatidylcholine source, fluxes, and turnover times in 3-day-old, 10-day-old, and adult rabbits. J Biol Chem 257:1805-1810

7. Jobe A 1977 The labeling and biological half-life of phosphatidylcholine in subcellular fractions of rabbit lung. Biochim Biophys Acta 489:440-453

8. Jobe A, Ikegami M, Glatz T, Yoshida Y, Diakomanolis E, Padbury J 1983 Saturated phosphatidylcholine secretion and the effect of natural surfactant on premature and term lambs ventilated for 2 days. Exp Lung Res 4:259-267

9. Chida N, Adams FH 1967 Incorporation of palmitate, glucose and choline into lecithin by fetal and newborn lamb lung. Pediatr Res 1:364-371

10. Cockshutt A, Possmayer F 1992 Metabolism of surfactant lipids and proteins in the developing lung. In: Robertson B, Van Golde LMG, Batenburg JJ, (eds) Pulmonary Surfactant: From Molecular Biology to Clinical Practice. Elsevier Science Publishers, Amsterdam, pp 339-377

11. Bunt JE, Zimmermann LJ, Wattimena JL, van Beek RH, Sauer PJ, Carnielli VP 1998 Endogenous surfactant turnover in preterm infants measured with stable isotopes. Am J Respir Crit Care Med 157:810-814

12. Cogo PE, Carnielli VP, Bunt JE, Badon T, Giordano G, Zacchello F, Sauer PJ, Zimmermann LJ 1999 Endogenous surfactant metabolism in critically ill infants measured with stable isotope labeled fatty acids. Pediatr Res 45:242-246

13. Bunt JE, Carnielli VP, Darcos Wattimena JL, Hop WC, Sauer PJ, Zimmermann LJ 2000 The effect in premature infants of prenatal corticosteroids on endogenous surfactant synthesis as measured with stable isotopes. Am J Respir Crit Care Med $162: 844-849$

14. Bunt JE, Carnielli VP, Janssen DJ, Wattimena JL, Hop WC, Sauer PJ, Zimmermann LJ 2000 Treatment with exogenous surfactant stimulates endogenous surfactant synthesis in premature infants with respiratory distress syndrome. Crit Care Med 28:3383-3388

15. Cavicchioli P, Zimmermann LJ, Cogo PE, Badon T, Giordano G, Torresin M, Zacchello F, Carnielli VP 2001 Endogenous surfactant turnover in preterm infants with respiratory distress syndrome studied with stable isotope lipids. Am J Respir Crit Care Med 163:55-60

16. Merchak A, Janssen D, Bohlin K, Patterson BW, Zimmerman LJ, Carnielli VP, Hamvas A 2002 Endogenous pulmonary surfactant metabolism is not affected by mode of ventilation in premature infants with respiratory distress syndrome. J Pediatr 140:693-698

17. Martini WZ, Chinkes DL, Barrow RE, Murphey ED, Wolfe RR 1999 Lung surfactant kinetics in conscious pigs. Am J Physiol 277:E187-E195

18. Bunt JEH, Carnielli VP, Seidner SR, Ikegami M, Wattimena JLD, Sauer PJJ, Jobe AH, Zimmermann LJI 1999 Metabolism of endogenous surfactant in premature baboons and effect of prenatal corticosteroids. Am J Respir Crit Care Med 160:1481-1485

19. Cogo PE, Zimmermann LJI, Rosso F, Tormena F, Piergiorgio G, Verlato G, Baritussio A, Carnielli VP 2002 Surfactant synthesis and kinetics in infants with congenital diaphragmatic hernia. Am J Respir Crit Care Med 166:154-158

20. Patterson CE, Rhoades RA 1989 Substrate utilization in the perinatal lung. Am J Physiol 257:L318-L330

21. Yeh YY 1991 Substrate utilization for phosphatidylcholine synthesis by type II pneumocytes of neonatal rats. Pediatr Res 30:55-61 
22. Sheehan PM, Yeh YY 1985 Pulmonary surfactant lipid synthesis from ketone bodies, lactate and glucose in newborn rats. Lipids 20:835-841

23. Hellerstein MK, Kletke C, Kaempfer S, Wu K, Shackleton CHL 1991 Use of mass isotopomer distributions in secreted lipids to sample lipogenic acetyl-CoA pool in vivo in humans. Am J Physiol 261:E479-E486

24. Chinkes DL, Aarsland A, Rosenblatt J, Wolfe RR 1996 Comparison of mass isotopomer dilution methods used to compute VLDL production in vivo. Am J Physiol 271:E373-E383

25. Merchak A, Patterson BW, Yarasheski KE, Hamvas A 2000 Use of stable isotope labeling technique and mass isotopomer distribution analysis of [(13)C]palmitate isolated from surfactant disaturated phospholipids to study surfactant in vivo kinetics in a premature infant. J Mass Spectrom 35:734-738

26. Mason RJ, Nellenbogen J, Clements JA 1976 Isolation of disaturated phosphatidylcholine with osmium tetroxide. J Lipid Res 17:281-284

27. Thibeault DW, Mabry SM, Ekekezie II, Truog WE 2000 Lung elastic tissue maturation and perturbations during the evolution of chronic lung disease. Pediatrics 106:1452-1459

28. Rosner B 1986 Fundamentals of Biostatistics. Duxbury Press, Boston

29. Martini WZ, Irtun O, Chinkes DL, Barrow RE, Wolfe RR 2001 Surfactant phosphatidylcholine in thermally injured pigs. Crit Care Med 29:1417-1422

30. Martini WZ, Irtun O, Chinkes DL, Barrow RE, Wolfe RR 2000 Glucose effects on lung surfactant kinetics in conscious pigs. Am J Physiol 279:E920-E926

31. Schmidt R, Meier U, Yabut-Perez M, Walmrath D, Grimminger F, Seeger W, Gunther A 2001 Alteration of fatty acid profiles in different pulmonary surfactant phospholipids in acute respiratory distress syndrome and sever pneumonia. Am J Respir Crit Care Med 163:95-100

32. Ohashi T, Pinkerton K, Ikegami M, Jobe AH 1994 Changes in alveolar surface area, surfactant protein A, and saturated phosphatidylcholine with postnatal rat lung growth. Pediatr Res 35:685-689

33. Dargaville PA, South M, Mc Dougall PN 1997 Pulmonary surfactant concentration during transition from high frequency oscillation to conventional mechanical ventilation. J Pediatr Child Health 33:517-521

34. Hallman M, Merritt TA, Pohjavuori M, Gluck L 1986 Effect of surfactant substitution on lung effluent phospholipids in respiratory distress syndrome: evaluation of surfactant phospholipid turnover, pool size, and the relationship to severity of respiratory failure. Pediatr Res 20:1228-1235

35. Jobe AH, Ikegami M, Jacobs HC, Jones SJ 1983 Surfactant pool sizes and severity of respiratory distress syndrome in prematurely delivered lambs. Am Rev Respir Dis 127:751-755

36. Torresin M, Zimmermann LJ, Cogo PE, Cavicchioli P, Badon T, Giordano G, Zacchello F, Sauer PJ, Carnielli VP 2000 Exogenous surfactant kinetics in infant respiratory distress syndrome: a novel method with stable isotopes. Am J Respir Crit Care Med 161:1584-1589

37. Janssen DJMT, Carnielli VP, Cogo PE, Seidner SR, Luijendijk IHI, Wattimena JLD, Jobe AH, Zimmermann LJI 2002 Surfactant phosphatidylcholine half-life and pool size measurements in premature baboons developing bronchopulmonary dysplasia Pediatr Res 52: 724-729 